\title{
Factors associated with overweight and obesity among adults in northeast Ethiopia: a cross-sectional study
}

This article was published in the following Dove Medical Press journal: Diabetes, Metabolic Syndrome and Obesity:Targets and Therapy

\author{
Samuel Dagne' \\ Yalemzewod Assefa Gelaw ${ }^{2}$ \\ Zegeye Abebe' \\ Molla Mesele Wassie' \\ 'Department of Human Nutrition, \\ Institute of Public Health, \\ College of Medicine and Health \\ Sciences, University of Gondar, \\ Gondar, Ethiopia; ${ }^{2}$ Department of \\ Epidemiology and Biostatistics, \\ Institute of Public Health, College \\ of Medicine and Health Sciences, \\ University of Gondar, Gondar, \\ Ethiopia
}

Objective: Currently, the growing prevalence of overweight and obesity is an emerging public health problem in middle- and low-income countries such as Ethiopia. However, the prevalence of overweight and obesity among Ethiopian adults who live in the major cities is not well documented. Therefore, the study aimed to assess the prevalence and factors associated with overweight and obesity among adults in Dessie town, northeast Ethiopia.

Subjects and methods: A community-based cross-sectional study was conducted from March 15 to April 10, 2015. A total of 751 adults aged 18-64 years were included. Multistage followed by systematic random sampling method was used to select the study participants. Both bivariable and multivariable ordinal logistic regression were done. The proportional odds ratio (POR) with a $95 \% \mathrm{CI}$ was reported to show the strength of association. A $P$-value $<0.05$ was considered statistically significant.

Results: Of all participants, $19.9 \%$ (95\% CI: 16.9\%, 23.1\%) were recorded to be overweight and $8.6 \%(95 \% \mathrm{CI}: 6.6 \%, 10.9 \%)$ to be obese. The odds of being overnourished (overweight or obese) were higher among adults who had snack intake habit (POR $=1.52$; 95 CI: 1.04, 2.20 ), drank alcohol ( $\mathrm{POR}=1.75 ; 95 \% \mathrm{CI}: 1.04,2.97)$, had higher wealth status ( $\mathrm{POR}=2.29$; 95\% CI: $1.26,4.19$ ), and were married (POR $=2.22 ; 95 \% \mathrm{CI}: 1.49,3.29)$ compared to their counterparts.

Conclusion: Compared to the previous local reports, the prevalence of overweight and obesity in the study area is high; this appears to be an emerging problem in Ethiopia. Hence, there is a need to develop a control and prevention strategy on potentially modifiable risk factors of overweight and obesity.

Keywords: overweight, obesity, adult, Dessie, Ethiopia

\section{Introduction}

Overweight and obesity are global problems that are increasing at an alarming and uncontrollable rate. According to the WHO, 2.3 billion adults are overweight and the prevalence is higher in females of childbearing age than males. ${ }^{1-4}$ Overweight and obesity are associated with numerous comorbidities of great public health concern, particularly cardiovascular diseases, type 2 diabetes, high blood pressure, high blood cholesterol, high triglycerides, certain types of cancer, and sleep apnea. ${ }^{5}$ In addition, the compromised quality of life resulting from overweight and obesity is related to higher medical, psychological, and social burden to the society. ${ }^{5}$

The global burden of overweight and obesity is recorded to be 2.8 million deaths per year and 35.8 million disability-adjusted life-years. Additionally, $44 \%$ of diabetes,
Correspondence: Zegeye Abebe Department of Human Nutrition, Institute of Public Health, College of Medicine and Health Sciences, University of Gondar, PO Box 196, Gondar, Ethiopia

$\mathrm{Tel}+251918605100$

Email zegeye24@gmail.com 
$23 \%$ of ischemic heart diseases, and $7 \%-41 \%$ of certain cancers are caused by overweight or obesity. ${ }^{7}$ Currently, overweight and obesity are becoming an emerging public health problem in developing countries, despite the continual high prevalence of undernutrition. ${ }^{8}$ In Africa, the body mass index (BMI) increased over time across all regions, which parallels the global average. However, the mean BMI was higher than the global average in northern and southern Africa. The prevalence of overweight and obesity is estimated to be $20 \%-50 \%$ by 2025 in Africa. ${ }^{9}$ For instance, reports show that in the adult populations, $20.8 \%$ of Nigerians are overweight, $31.3 \%$ of South Africans are obese, and $37.1 \%$ and $27.8 \%$ of Ghanaians are overweight and obese, respectively. ${ }^{10-12}$

Primarily, diet, physical activity level, and environmental factors are responsible for overweight and obesity. The total calorie consumption of an individual has been found to be related to obesity. Consumption of sweetened drinks or energy-dense, big-portion, and fast-food meals is believed to be contributing to the rising rates of obesity. ${ }^{13}$ In addition, genetics and socioeconomic status have also contributed to overweight and obesity. ${ }^{14}$

In the past several years, overweight and obesity were not a common problem in Ethiopia. But recently, the prevalence of adult overweight and obesity has increased from $4 \%$ in 2000 to $6 \%$ in $2016 .{ }^{15,16}$ Similarly, different pocket area studies showed that the prevalence of adult overweight ranges from $16.1 \%$ to $25.3 \%$ and obesity ranges from $5.6 \%$ to $16.2 \% .{ }^{17-20}$ As it is known, overweight and obesity have become a complex problem resulting from a combination of genetic, behavioral, cultural, and environmental influences; this calls for not only behavioral changes at individual levels, but also changes in public policy, social environment, and cultural norms. However, most nutritional interventions in Ethiopia are focused on addressing childhood undernutrition. Hence, identifying the risk factors which contribute to the rapid increment of overweight and obesity will have a paramount importance in the prevention and control of these emerging public challenges in Ethiopia. ${ }^{21}$ Therefore, this study was targeted to assess the prevalence of overweight and obesity and its associated factors among adults in Dessie town, northeast Ethiopia.

\section{Methods}

\section{Study setting and design}

A community-based cross-sectional study design was carried out from March 15 to April 10, 2015. The study was conducted in Dessie town, a town with a population of 203,095, which is located in the northeastern part of Ethiopia, $400 \mathrm{~km}$ away from Addis Ababa, the Ethiopian capital. Of the adult population numbering $85,521,41,100$ were males and 44,421 were females. The administration contains 16 kebeles (the smallest administration unit in Ethiopia).

\section{Sample size and sampling procedure}

All adults aged 18-64 years who were living in Dessie town were eligible for the study, except pregnant women and women who gave birth in the last 6 months, adults with spinal problems (kyphosis, lordosis, scoliosis, and kyphoscoliosis), and those who were edematous, critically ill, and unable to communicate. The sample size of the study was computed using Epi Info version 7 by considering the following assumptions: prevalence of overweight $20.6 \%,{ }^{20}$ level of significance $95 \%$, 4\% margin, and 1.5 design effect. Finally, the sample size of 805 was obtained by adding $5 \%$ non-response rate. Multistage sampling was used to select the study participants. Initially, 4 kebeles were selected, of the overall 16 kebeles, by using lottery method. The total number of households in each kebele was obtained from the kebele administrators. The proportionate-to-population size calculation was used to select the number of households in each kebele. Next, the sampling interval $(\mathrm{K})$ was determined by dividing the total number of households in each kebele by the allocated sample size to each kebele. A lottery method was used to determine the starting households in each of the four kebeles. Consequently, the $\mathrm{K}$ value was added until the allocated sample size to each kebele was reached. When more than one eligible adult was found in the selected households, the lottery method was used to select one eligible adult.

\section{Data collection instrument and procedure}

A structured interviewer-administered questionnaire was used to collect data. The questionnaire was first prepared in English and was translated into the local language (Amharic) and finally back translated to English to maintain consistency. The questionnaire consisted of information on socioeconomic characteristics, dietary history, physical activity, and alcohol intake. The global physical activity questionnaire analysis guide ${ }^{21}$ and the WHO steps instruments for chronic disease risk surveillance questionnaire were used after minor modifications. $^{22}$

A pretest was done on $5 \%$ of the sample from the study area. A 2-day training on how to conduct the interview and perform anthropometric measurements was given for data collectors and supervisors. A total of four data collectors and two supervisors (public health experts) were recruited for the 
study. Daily supervision and feedback were carried out by the investigators and supervisors during the entire data collection period. Anthropometric measurement tools were calibrated before measurement to maintain the accuracy of the data.

\section{Measurements}

\section{Weight and height}

The weight was measured with the participants in a standing position without shoes and with light clothing using a beam balance to the nearest $10 \mathrm{~g}$. Similarly, the height was measured to the nearest $0.1 \mathrm{~cm}$ with the participants in an upright position with the head in the Frankfort plane. Then, BMI of the adults was calculated by dividing the body weight by height in meters squared $\left(\mathrm{kg} / \mathrm{m}^{2}\right)$. BMI values of $18.5-24.9$, $25-29.9$, and $\geq 30 \mathrm{~kg} / \mathrm{m}^{2}$ were used to classified adults as normal, overweight, and obese, respectively. ${ }^{21}$

\section{Assessment of dietary habit}

Respondents were asked about their dietary habit using a dichotomous yes and no questionnaire; if the respondent answered yes, then further questions were asked about how frequent per week and per month specific food consumption occurred. This included their intake of snacks between meals.

\section{Wealth index}

The household's wealth status was determined from the key household asset ownership variables (household assets such as quantity of cereal products, and house, livestock, and agricultural land ownership). First, the variables were coded between 0 and 1 . Then, the variables were entered and analyzed using Principal Component Analysis, and those variables having a communality value of $>0.5$ were used to produce factor scores. Finally, the factor scores were summed and ranked into tertiles as poor, medium, and rich based on the lower, middle, and higher score tertiles, respectively.

\section{Physical activity}

The WHO standard total physical activity calculation guide was used to assess the physical activity level of participants. Then, the activity levels were determined according to the three settings (or domains). These included activity at work, travel to and from places and recreational activities, and sedentary behavior. Finally, moderate physical activity was defined as low-impact aerobic exercise classes, brisk walking or hiking, and recreational team sports (volleyball, soccer, and so on). Running or jogging, high-intensity aerobic classes, competitive full-field sports (soccer), and basketball were considered as vigorous physical activity. No exercise or no physical activity was classified as a low physical activity.

\section{Alcohol intake}

Alcohol intake was assessed using a 1-month recall period. Differences in prevalence of obesity or overweight between respondents who consumed alcoholic beverages and the respondents who did not consume alcohol at all were found; however, the quantity of alcohol intake was not accounted for or recorded. ${ }^{31}$

\section{Data processing and analysis}

The collected data were reviewed and entered into Epi Info version 7 and exported to SPSS version 20 statistical software for analysis. Descriptive statistics were carried out and the result was presented using text and tables. An ordinal logistic regression model was used to identify factors associated with overnutrition. The ordinal logistic regression model was used because the nutritional status determined by using BMI is an ordinal data (normal vs overweight vs obese). The proportional odds model (POM), equivalent to performing two binary logistic regression analyses simultaneously, was fitted to identify factors associated with overweight and obesity. The necessary assumptions for POM were checked using chisquared and parallel line tests. The chi-squared test for the proportional odds assumption was employed to see whether the model assumptions were violated or not. The Pearson chi-squared goodness-of-fit test showed that the observed data were consistent with the fitted model $(P=0.838)$. Moreover, the appropriateness of the POM was evaluated by the parallel line test, and it revealed that the general model did not significantly differ from the fitted POM $(P=0.406)$, indicating that the model was not violated. Bivariable analyses were performed between the dependent and independent variables. All variables with a $P$-value $<0.25$ in the bivariable analysis were fitted into the multivariable POM to control for confounding effects. Adjusted proportional OR with a 95\% CI was used to evaluate the strength of statistical association between explanatory and outcome variables. All tests were two-sided, and variables with $P$-values $<0.05$ in the multivariable analysis were considered to be statistically significant.

\section{Results \\ Sociodemographic and economic characteristics of respondents}

A total of 751 adults, with a response rate of $93.29 \%$, were involved in the study. About $51.4 \%$ and $48.9 \%$ of the study participants were female and attended college and above, 
respectively. More than half of the respondents, 433 (57.7\%), had a family size of more than four members. Nearly half, 363 (48.3\%), of the respondents came from economically low households (Table 1).

\section{Dietary habits, alcohol intake, and physical activity}

A substantially higher proportion, 631 (97.4\%), of the study participants ate cereal-based foods. Similarly, more than half $(52.9 \%)$ of the study participants consumed fruits one to four times per week. Milk and milk products, fatty foods, legumes, and sweets were commonly used in the study setting (Table 2). Among the study participants, 243 (32.4\%) respondents consumed alcohol. Regarding the physical activity of the respondents, almost all respondents, 744 (99.1\%), were engaged in low to moderate workplace activities. However, three-fourths (74.8\%) of the study participants had no leisure time physical activity and about $55.4 \%$ spent three or more hours sitting without any exercise. Concerning their mode of transportation, $350(46.6 \%)$ traveled by car, while 283 $(37.7 \%)$ traveled on foot.

\section{Prevalence of overweight and obesity}

In this study, the prevalence of overweight and obesity was 19.9\% (95\% CI: $16.9 \%, 23.1 \%$ ) and 8.6\% (95\% CI: 6.6\%, $10.9 \%$ ), respectively. The combined prevalence of overweight and obesity was $28.5 \%$ (95\% CI: $25.3,31.9)$. A similar proportion of males and females were overweight (20.2\% male vs $18.1 \%$ female) and obese ( $8.8 \%$ male vs $8.6 \%$ female). However, about $78(10.4 \%)$ of the study participants were chronic energy deficient.

\section{Factors associated with the level of nutritional status}

From the final model, chi-squared test provided a chi-squared value of 819.121 ( $P$-value 0.838 ); this implied that the model had a good fit. Furthermore, the chi-squared test of parallelism showed that the ORs were constant across all cutoff

Table I Sociodemographic and economic characteristics of adults, Dessie district, northeast Ethiopia, 2015

\begin{tabular}{|c|c|c|c|c|}
\hline \multirow[t]{2}{*}{ Variables } & \multicolumn{3}{|c|}{ Nutritional status } & \multirow[t]{2}{*}{ Total frequency, n (\%) } \\
\hline & Normal, n (\%a) & Overweight, n (\%ª) & Obese, n (\%a) & \\
\hline \multicolumn{5}{|l|}{ Religion } \\
\hline Orthodox & $231(66.4)$ & $82(23.6)$ & $35(10.0)$ & $348(5 । .7)$ \\
\hline Muslim & $240(78.4)$ & $44(14.4)$ & $22(7.2)$ & $306(45.5)$ \\
\hline Protestant & $9(47.4)$ & $8(42.1)$ & $2(10.5)$ & $19(2.8)$ \\
\hline \multicolumn{5}{|l|}{ Marital status } \\
\hline Currently married & $278(65.4)$ & $99(23.3)$ & $48(11.3)$ & $425(63.2)$ \\
\hline Currently unmarried & $202(81.5)$ & $35(14.1)$ & II (4.4) & $248(36.8)$ \\
\hline \multicolumn{5}{|l|}{ Sex } \\
\hline Male & $403(70.9)$ & $115(20.2)$ & $50(8.9)$ & $568(84.4)$ \\
\hline Female & $77(73.3)$ & $19(18.1)$ & $9(8.6)$ & $105(15.6)$ \\
\hline \multicolumn{5}{|l|}{ Occupation } \\
\hline Merchant & $192(73.6)$ & $49(18.8)$ & $20(7.6)$ & $261(38.8)$ \\
\hline Government employee & $185(66.5)$ & $59(21.2)$ & $34(12.3)$ & $278(4 I .3)$ \\
\hline Daily worker & $33(73.3)$ & $12(26.7)$ & $0(0)$ & $45(6.7)$ \\
\hline Other ${ }^{c}$ & $70(78.6)$ & $14(15.7)$ & $5(5.7)$ & 89 (13.2) \\
\hline \multicolumn{5}{|l|}{ Educational status } \\
\hline Cannot write and read & $34(80.9)$ & $5(11.9)$ & $3(7.1)$ & $42(6.2)$ \\
\hline Primary & $80(82.5)$ & $13(13.4)$ & $4(4.1)$ & $97(14.4)$ \\
\hline Secondary & $129(63.5)$ & $5 I(25.1)$ & $23(11.4)$ & $203(30.2)$ \\
\hline College and above & $237(71.6)$ & $65(19.6)$ & $29(8.8)$ & $331(49.2)$ \\
\hline \multicolumn{5}{|l|}{ Wealth status } \\
\hline Rich & $35(57.4)$ & $15(24.6)$ & $11(18.0)$ & $61(9.1)$ \\
\hline Medium & $201(66.8)$ & $67(22.3)$ & $33(10.9)$ & $301(46.2)$ \\
\hline Poor & $244(78.5)$ & $52(16.7)$ & $15(4.8)$ & $311(46.2)$ \\
\hline
\end{tabular}

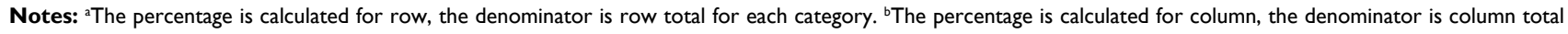
for each category. 'Students, farmer. 
Table 2 Dietary habits among adults in Dessie district, northeast Ethiopia, 2015

\begin{tabular}{|c|c|c|c|c|}
\hline \multirow[t]{2}{*}{ Dietary habits } & \multicolumn{3}{|c|}{ Nutritional status } & \multirow{2}{*}{$\begin{array}{l}\text { Total frequency, } \\
\text { n (\%) }\end{array}$} \\
\hline & Normal, n $\left(\%^{\mathrm{a}}\right)$ & Overweight, n (\%a) & Obese, n (\%a) & \\
\hline \multicolumn{5}{|c|}{ Cereal consumption } \\
\hline Daily & $470(71.8)$ & $129(19.7)$ & $56(8.5)$ & $655(97.3)$ \\
\hline Weekly & $6(50.0)$ & $4(33.3)$ & $2(16.7)$ & $12(1.8)$ \\
\hline Monthly & $4(66.7)$ & I (I6.7) & $I(16.6)$ & $6(0.9)$ \\
\hline \multicolumn{5}{|l|}{ Fruits } \\
\hline Daily & $120(71.0)$ & $31(18.3)$ & $18(10.7)$ & $169(25.1)$ \\
\hline Weekly & $247(68.6$ & $86(23.9)$ & $27(7.5)$ & $360(53.5)$ \\
\hline Monthly & $81(76.4)$ & $13(12.3)$ & $12(11.3)$ & $106(15.8)$ \\
\hline Never use & $32(84.2)$ & $4(10.5)$ & $2(5.3)$ & $38(5.6)$ \\
\hline \multicolumn{5}{|l|}{ Vegetable } \\
\hline Daily & $124(64.9)$ & $45(23.6)$ & $22(11.5)$ & $191(28.4)$ \\
\hline Weekly & $280(74.1)$ & $67(17.7)$ & $31(8.2)$ & $378(56.2)$ \\
\hline Monthly & $57(70.4)$ & $18(22.2)$ & $6(7.4)$ & $81(12)$ \\
\hline Never use & $19(82.6)$ & $4(17.4)$ & $0(0)$ & $23(3.4)$ \\
\hline \multicolumn{5}{|c|}{ Milk and milk products } \\
\hline Daily & $133(66.2)$ & $46(22.9)$ & $22(11.5)$ & $201(29.9)$ \\
\hline Weekly & $151(72.6)$ & $42(20.2)$ & $15(7.2)$ & $208(30.9)$ \\
\hline Monthly & $112(72.3)$ & $30(19.4)$ & $13(8.4)$ & $155(23)$ \\
\hline Never use & $84(77.1)$ & $16(14.7)$ & $9(8.3)$ & $109(16.2)$ \\
\hline \multicolumn{5}{|l|}{ Fats } \\
\hline Daily & $53(58.2)$ & $23(25.3)$ & $15(16.5)$ & $91(13.5)$ \\
\hline Weekly & $206(68.9)$ & $64(21.4)$ & $29(9.7)$ & $299(44.4)$ \\
\hline Monthly & $173(76.5)$ & $44(19.5)$ & $9(4.0)$ & $226(33.6)$ \\
\hline Never use & $48(84.2)$ & $3(5.3)$ & $6(10.5)$ & $57(8.5)$ \\
\hline \multicolumn{5}{|l|}{ Meat, egg, and fish } \\
\hline Daily & $13(56.5)$ & $4(17.4)$ & $6(26.1)$ & $23(3.4)$ \\
\hline Weekly & $84(65.5)$ & $36(28.1)$ & $8(6.4)$ & $128(19)$ \\
\hline Monthly & $140(72.9)$ & $38(19.8)$ & $14(7.3)$ & $192(28.5)$ \\
\hline Never use & $243(73.6)$ & $56(17.0)$ & $31(9.4)$ & $330(49)$ \\
\hline \multicolumn{5}{|l|}{ Snack use } \\
\hline Yes & $265(74.4)$ & $68(19.1)$ & $23(6.5)$ & $356(52.9)$ \\
\hline No & $215(67.8)$ & $66(20.8)$ & $36(13.4)$ & $317(47.1)$ \\
\hline \multicolumn{5}{|c|}{ Number of meals per day } \\
\hline Once & $2(100)$ & $0(0)$ & $0(0)$ & $2(0.3)$ \\
\hline Twice & $96(73.8)$ & $27(20.8)$ & $7(5.4)$ & $130(19.3)$ \\
\hline Three times & $370(70.3)$ & $106(20.2)$ & $50(9.5)$ & $526(78.2)$ \\
\hline Four and above & $12(80)$ & $\mathrm{I}(6.7)$ & $2(13.3)$ & $15(2.2)$ \\
\hline \multicolumn{5}{|c|}{ Frequency of soft drink use } \\
\hline Weekly & $142(75.5)$ & $37(19.7)$ & $9(4.8)$ & $188(27.9)$ \\
\hline Three times weekly & $108(76.1)$ & $23(16.2)$ & II (7.7) & $142(21.1)$ \\
\hline Two times weekly & $104(72.7)$ & $23(16.1)$ & $16(11.2)$ & $143(2 \mid .2)$ \\
\hline Never use & $126(63.0)$ & $51(25.5)$ & $23(11.5)$ & $200(29.7)$ \\
\hline
\end{tabular}

Notes: ${ }^{a}$ The percentage is calculated for row, the denominator is row total for each category. ${ }^{\circ}$ The percentage is calculated for column, the denominator is column total for each category. 
points of nutritional status for the final model at a 5\% level $(P$-value $=0.406)$. Accordingly, the results of POM revealed that the risk of being in the higher order of nutritional status (overweight or obesity) was 1.52 times ( $\mathrm{POR}=1.52$; $95 \mathrm{CI}$ : $1.04,2.20)$ higher among adults who had snack intake habit compared to adults who had no habit of snack intake. The risk of developing obesity or overweight was 1.75 times ( $\mathrm{POR}=1.75 ; 95 \mathrm{CI} \%$ : 1.07, 2.97) higher among adults who consumed alcohol compared with adults who did not drink alcohol at all. As compared to the poor adults, the risk of being overweight or obese was 2.29 times higher among rich adults. Similarly, married adults were 2.22 times more likely to be overweight or obese ( $\mathrm{POR}=2.22 ; 95 \mathrm{CI}: 1.49,3.29$ ) compared to the unmarried adults (Table 3 ).

\section{Discussion}

Identification of potentially modifiable risk factors of overweight and obesity is an important step to prevent and control the epidemic dimension of overweight and obesity in developing countries. In this study, the prevalence of overweight and obesity was $19.9 \%$ (95\% CI: $16.9 \%, 23.1 \%)$ and $8.6 \%$ (95\% CI: $6.6 \%, 10.9 \%)$, respectively. In addition, marital status,

Table 3 Factors associated with the level of nutritional status among adults, Dessie district, northeast Ethiopia, 2015

\begin{tabular}{|c|c|c|c|c|c|c|c|}
\hline \multirow[t]{2}{*}{ Variables } & \multicolumn{3}{|c|}{ Nutritional status } & \multirow[t]{2}{*}{ CPOR } & \multirow[t]{2}{*}{$P$-value } & \multirow[t]{2}{*}{ aPOR } & \multirow[t]{2}{*}{$P$-value } \\
\hline & $\begin{array}{l}\text { Obesity, } \\
n\left(\%^{a}\right)\end{array}$ & $\begin{array}{l}\text { Overweight, } \\
\text { n }\left(\%^{a}\right)\end{array}$ & $\begin{array}{l}\text { Normal, } \\
\text { n (\%) }\end{array}$ & & & & \\
\hline \multicolumn{8}{|l|}{ Mode of transport } \\
\hline Car & $26(9.4)$ & $74(26.6)$ & $178(64.0)$ & $1.34(0.82,2.19)$ & 0.250 & $1.12(0.66,1.89)$ & 0.673 \\
\hline Foot & $20(7.0)$ & $40(14.0)$ & $227(79.0)$ & $1.06(0.67,1.68)$ & 0.810 & $0.96(0.59,1.56)$ & 0.876 \\
\hline Both & $13(12.0)$ & $20(18.5)$ & $75(69.5)$ & 1.00 & & 1.00 & \\
\hline \multicolumn{8}{|l|}{ Educational status } \\
\hline College and above & 237 (7I.6) & $65(19.6)$ & $29(18.8)$ & $0.60(0.27,1.34)$ & 0.217 & $0.61(0.27,1.42)$ & 0.253 \\
\hline Secondary & $129(63.5)$ & $51(25.1)$ & $23(11.4)$ & $0.42(0.18,0.95)$ & 0.038 & $0.47(0.19,1.09)$ & 0.077 \\
\hline Primary & $80(82.5)$ & $13(13.4)$ & $4(4.1)$ & $1.14(0.45,2.88)$ & 0.778 & $1.00(0.38,2.62)$ & 0.992 \\
\hline Unable to read and write & $34(81.0)$ & $5(12.0)$ & $3(7.0)$ & 1.00 & & 1.00 & \\
\hline \multicolumn{8}{|l|}{ Wealth status } \\
\hline Rich & $35(57.4)$ & $15(24.6)$ & II (I8.0) & $2.90(1.66,5.06)$ & $<0.0001$ & $2.29(1.26,4.19)$ & $0.007^{k *}$ \\
\hline Medium & $201(66.8)$ & $67(22.3)$ & $33(10.9)$ & I.56 (0.9I, 2.69) & 0.105 & $1.38(0.77,2.44)$ & 0.274 \\
\hline Poor & $244(78.5)$ & $52(16.7)$ & $15(4.8)$ & 1.00 & & 1.00 & \\
\hline \multicolumn{8}{|l|}{ Snack intake } \\
\hline Yes & $265(44.3)$ & 68 (II.4) & $265(44.3)$ & $1.43(1.02,1.98)$ & 0.024 & $1.52(1.04,2.20)$ & $0.044^{* *}$ \\
\hline No & $215(43.3)$ & $66(13.4)$ & $215(44.3)$ & 1.00 & & 1.00 & \\
\hline \multicolumn{8}{|l|}{ Alcohol intake } \\
\hline Yes & $53(8.8)$ & $110(18.3)$ & 439 (72.9) & $1.77(1.07,2.90)$ & .024 & $1.75(1.04,2.97)$ & $.037^{k *}$ \\
\hline No & $6(8.5)$ & $24(33.8)$ & $4 I(57.7)$ & 1.00 & & 1.00 & \\
\hline \multicolumn{8}{|l|}{ Vegetable consumption } \\
\hline Daily & $124(65.0)$ & $45(23.5)$ & 22 (II.5) & $0.37(0.12,1.14)$ & 0.083 & $0.33(0.10,1.12)$ & 0.073 \\
\hline Weekly & $280(74.1)$ & $67(17.7)$ & $31(8.2)$ & $0.56(0.18,1.73)$ & 0.317 & $0.41(0.12,1.32)$ & 0.137 \\
\hline Monthly & $57(70.4)$ & $18(22.2)$ & $6(7.4)$ & $0.48(0.15,1.59)$ & 0.233 & $0.37(0.10,1.27)$ & 0.115 \\
\hline Never & $19(79.2)$ & $4(16.7)$ & $\mathrm{I}(4.1)$ & 1.00 & & 1.00 & \\
\hline \multicolumn{8}{|l|}{ Marital status } \\
\hline Currently married & $278(65.4)$ & $99(23.3)$ & $48(11.3)$ & $2.35(1.62,3.42)$ & $<0.0001$ & $2.22(1.49,3.29)$ & $<0.000 \mathrm{I}^{* *}$ \\
\hline Currently unmarried & $202(81.5)$ & $35(14.1)$ & II (4.4) & 1.00 & & 1.00 & \\
\hline \multicolumn{8}{|l|}{ Physical activity } \\
\hline Low & $50(8.9)$ & 117 (20.7) & $397(7.4)$ & $0.85(0.16,4.55)$ & 0.152 & $0.98(0.17,5.72)$ & 0.983 \\
\hline Moderate & $9(8.8)$ & $15(14.7)$ & $78(76.5)$ & $1.13(0.20 .6 .35)$ & 0.888 & $1.16(0.18,7.08)$ & 0.873 \\
\hline High & I (I2.5) & $2(25.0)$ & $5(62.5)$ & 1.00 & & 1.00 & \\
\hline
\end{tabular}

Notes: a The percentage is calculated for row, the denominator is row total for each category. "Significant at $P$-value $<0.05$. Abbreviations: aPOR, adjusted proportional odds ratio; cPOR, crude proportional odds ratio. 
snacking, alcohol drinking, and economic status were the main contributory factors of overweight and obesity.

The finding is comparable with the prevalence of overweight and obesity reported in Benin $(19.2 \%)^{23}$ and Nigeria $(20.8 \%) .{ }^{12}$ However, it was higher than the prevalence reported from Addis Ababa (9.8\%). ${ }^{24}$ This might be due to the difference in the dietary habit of the study participants; increased consumption of obesogenic and energy-dense foods in the study population may contribute to the discrepancy in the prevalence of overweight and obesity.

Furthermore, the prevalence of overweight and obesity in our study was lower than those reported in studies from developed countries such as USA, Canada, Greece, and Italy ${ }^{25-27}$ This might be because adults in developed countries may consume energy-dense foods more frequently than adults living in developing countries. In addition, consumption of mainly cereal-based monotonous diet, having a low household income to buy food commodities, and having a relatively non-sedentary behavior among adults in the study setting may contribute to the lower prevalence of overweight and obesity in the study area. Furthermore, cultural restriction of some animal food items in the fasting period of orthodox Christians may contribute to the lower consumption of energy-dense foods and associated lower prevalence of overweight and obesity as compared to adults in other countries.

In line with the established fact, ${ }^{28}$ this survey also confirmed that the risk of being in the higher orders of nutritional status was higher among rich adults compared to poor adults. This finding was also reproducible with the results from different developing countries such as India and Kenya. ${ }^{29,30}$ Adults with high income levels have a higher risk of expose to energy-dense foods and a sedentary way of life. ${ }^{9}$ Similar results were also reported from Vietnam ${ }^{31}$ and Mexico, ${ }^{25}$ where an increased risk of obesity was found among wealthier families. This may be related to changes in the dietary habits of wealthier adults. Adults from higher socioeconomic class are known to adopt a western lifestyle, which often times leads to greater intake of high fat and high caloric diet; these tendencies may substitute the healthy traditional diet (cereals, fruit, vegetables, etc). ${ }^{32}$ In addition, patterns of high-energy expenditure among the poor and the cultural values favoring a larger body size may contribute to positive energy balance. ${ }^{33}$ Furthermore, food purchasing ability of the household is determined by income, and adults from the highest income group had a probability of purchasing energy-dense foods. ${ }^{34}$

The result also showed that the risk of being overweight and obese was higher among adults who consumed alcohol compared to adults who did not consume alcohol. There are several sources of evidence that suggest the potential influence of alcohol on weight gain. When a person consumes alcohol, the caloric intake increases and it causes weight gain. ${ }^{35}$ This relationship between alcohol intake and weight gain is probably due to the relatively high energy content of ethanol compared to other macronutrients. Pure ethanol has an energy density of $7.1 \mathrm{kcal} / \mathrm{g}$, while the energy density of lipids (fat) is $9 \mathrm{kcal} / \mathrm{g}$; proteins and carbohydrates have an energy density of $4 \mathrm{kcal} / \mathrm{g} .{ }^{36}$ Excessive consumption of ethanol may result in a positive energy balance, which may, over time, result in being overweight or obese.

The results of this study also showed that marital status had a significant association with the occurrence of overweight and obesity. Based on the result, married adults were found in higher order of nutritional status as compared to unmarried adults. Even if the exact linking mechanism of marital status and overweight and obesity is not completely understood, the possible explanation is that married adults pay less focus on the nutritional issue, including being attractive and physically active. ${ }^{37}$ Married individuals have more social support and increased energy-dense regular eating patterns, which may lead to overweight and obesity.

In this study, the odds of being in the higher order of nutritional status were higher among adults who had snack intake habit compared to their counterparts. This result is supported by other similar studies done in Hawasa and Gondar which showed that having a snacking habit had a key role in the incidence of overweight and obesity. ${ }^{38,39}$ A consistent effect was also found among adolescent and early adult subjects in Saudi Arabia. ${ }^{40}$ In addition, some studies in the developed countries indicated that consuming a snack between meals increases the total daily energy intake, and thus body weight. Otherwise, other studies have suggested that having a snacking habit is not related to weight gain, but the nature of snacking is a matter of concern. ${ }^{41}$ Snack intake provides few calories, but consumption of several snacks contributes to high caloric intake. ${ }^{42}$ Even though the prevalence and risk factors associated with overweight and obesity in adults were assessed using representative data, the study has its own limitations. Frist, due to the cross-sectional nature of the study design, establishing a cause-effect relationship becomes difficult. Second, the quantity of alcohol consumed was not recorded and the measurement of fat and fat-free mass was not done.

In conclusion, compared to the previous local reports, the prevalence of overweight and obesity in this study was found to be high in the study area. Consuming alcohol, high economic status, and snacking were positively associated with the higher order of nutritional status. However, being an 
unmarried adult is negatively associated with higher orders of nutritional status. This finding is useful for the planning of health and nutrition programs as well as intervention strategies to combat adult overweight and obesity. Therefore, there is a need to develop a control and prevention strategy on potentially modifiable risk factors of overweight and obesity. Furthermore, including the measurement of frequency and quantity of alcohol consumption, and body composition is recommended in future study.

\section{Ethical considerations and consent to participate}

Ethical clearance was obtained from the Institutional review board of the University of Gondar. Permission was obtained from Desse City Administration Office. Informed oral consent was obtained from each study subject after the data collectors clearly explained the aims of the study. Respondents were also informed that they could refuse or discontinue participation at any time. Information was recorded anonymously to maintain confidentiality and privacy of respondent. Also, this study was conducted in accordance with the Declaration of Helsinki.

\section{Data sharing statement}

Due to ethical restrictions and privacy concerns, a dataset is available upon request from the author Zegeye Abebe: zegeye24@gmail.com

\section{Acknowledgments}

The authors would like to thank all respondents for their willingness to participate in the study. They are also grateful to the Dessie Zonal Health Department and the University of Gondar for material support. Authors' appreciations go to data collectors for their unreserved contribution in data collection activities. Finally, the authors would like to thank Rebekah MaldonadoNofziger and Franziska Gorke for language editing.

\section{Author contributions}

All authors contributed to data analysis, drafting and revising the article, gave final approval of the version to be published, and agree to be accountable for all aspects of the work.

\section{Disclosure}

The authors report no conflicts of interest in this work.

\section{References}

1. Ma RC, Schmidt MI, Tam WH, McIntyre HD, Catalano PM. Clinical management of pregnancy in the obese mother: before conception, during pregnancy, and post partum. Lancet Diabetes and Endocrinol. 2016;4(12):1037-1049.
2. Ha DT, Feskens EJ, Deurenberg P, Mai LB, Khan NC, Kok FJ. Nationwide shifts in the double burden of overweight and underweight in Vietnamese adults in 2000 and 2005: two national nutrition surveys. BMC Public Health. 2011;11(1):62.

3. WHO. Obesity and Overweight. Geneva: WHO; 2011. Available from https://www.who.int/news-room/fact-sheets/detail/obesity-andoverweight. Accessed March 5, 2019.

4. Ng M, Fleming T, Robinson M, et al. Global, regional, and national prevalence of overweight and obesity in children and adults during 1980-2013: a systematic analysis for the Global Burden of Disease Study 2013. Lancet. 2014;384(9945):766-781.

5. Engeland A, Bjørge T, Søgaard AJ, Tverdal A. Body mass index in adolescence in relation to total mortality: 32-year follow-up of 227,000 Norwegian boys and girls. Am J Epidemiol. 2003;157(6): 517-523.

6. Malik VS, Schulze MB, Hu FB. Intake of sugar-sweetened beverages and weight gain: a systematic review. Am J Clin Nutr. 2006;84(2): 274-288.

7. World Health Organization. Mortality and burden of disease attributable to selected major risks. Geneva: World Health Organization; 2009. Available from https://apps.who.int/iris/handle/10665/44203. Accessed March 5, 2019.

8. Tsiros MD, Coates AM, Howe PR, Grimshaw PN, Buckley JD. Obesity: the new childhood disability? Obese Rev. 2011;12(1):26-36.

9. Victora CG, Adair L, Fall C, et al. Maternal and child undernutrition: consequences for adult health and human capital. Lancet. 2008;371(9609):340-357.

10. Benkeser RM, Biritwum R, Hill AG. Prevalence of overweight and obesity and perception of healthy and desirable body size in urban Ghanaian women. Ghanaian Medical Journal. 2012;46(2): 66-75.

11. WHO. Non-communicable Diseases (NCD) Country Profiles. 2014. Available from https://www.who.int/nmh/publications/ncd-profiles-2014/en/. Accessed March 5, 2019.

12. Adebayo RA, Balogun MO, Adedoyin RA, Obashoro-John OA, Bisiriyu LA, Abiodun OO. Prevalence and pattern of overweight and obesity in three rural communities in southwest Nigeria. Diabetes, Metabolic Syndrome and Obesity: Targets and Therapy. 2014;7:153-158.

13. Olsen N, Heitmann B. Intake of calorically sweetened beverages and obesity. Obesity Reviews. 2009;10:68-75.

14. Zhang H, Xu H, Song F, Xu W, Pallard-Borg S, Qi X. Relation of socioeconomic status to overweight and obesity: a large population-based study of Chinese adults. Ann Hum Biol. 2017;44(6):495-501.

15. Central Statistical Agency [Ethiopia] and ICF International. Ethiopia Demographic and Health Survey 2011. Addis Ababa, Ethiopia and Calverton, Maryland, USA: Central Statistical Agency and ICF International. 2016: available from https://dhsprogram.com/pubs/pdf/FR328/ FR328.pdf. Accessed March 5, 2019.

16. Central Statistical Agency [Ethiopia] and ICF International. Ethiopia Demographic and Health Survey. Addis Ababa, Ethiopia and Calverton, Maryland, USA: Central Statistical Agency and ICF International. 2000. Available from https://dhsprogram.com/pubs/pdf/PR10/PR10. pdf. Accessed March 5, 2019.

17. Abrha S, Shiferaw S, Ahmed KY. Overweight and obesity and its sociodemographic correlates among urban Ethiopian women: evidence from the 2011 EDHS. BMC Public Health. 2016;16(1):636.

18. Moges B, Amare B, Fantahun B, Kassu A. High prevalence of overweight, obesity, and hypertension with increased risk to cardiovascular disorders among adults in northwest Ethiopia: a cross sectional study. BMC Cardiovascular Disorders. 2014;14:155.

19. Shegaze M, Wondafrash M, Alemayehu AA, et al. Magnitude and Determinants of Overweight and Obesity among High School Adolescents in Addis Ababa, Ethiopia. Journal of Food and Nutrition Sciences. 2015;3(5):166-173.

20. Tebekaw Y, Teller C, Colón-Ramos U. The burden of underweight and overweight among women in Addis Ababa, Ethiopia. BMC Public Health. 2014;14:1126. 
21. WHO. Data on overweight and obesity, mean BMI, healthy diets and physical inactivity. Geneva: WHO; 2012. Available from https:// www.who.int/news-room/fact-sheets/detail/obesity-and-overweight. Accessed March 5, 2019.

22. WHO. Global physical activity questionnaire (GPAQ) analysis guide. 2011. Available from https://www.who.int/ncds/surveillance/steps/ resources/GPAQ_Analysis_Guide.pdf. Accessed March 5, 2019.

23. Gbary AR, Kpozehouen A, Houehanou YC, et al. Prevalence and risk factors of overweight and obesity: findings from a cross-sectional community-based survey in Benin. Glob Epidemi Obes. 2014;2(3):6-9.

24. Zeleke A. Prevalence of childhood and adolescent overweight and obesity among elementary school students in Addis Ababa: Double burden of malnutrition in Ethiopia. Addis Ababa University. 2012.

25. Flegal KM, Ogden CL, Wei R, Kuczmarski RL, Johnson CL. Prevalence of overweight in US children: comparison of US growth charts from the Centers for Disease Control and Prevention with other reference values for body mass index. Am J Clin Nutr. Jun 2001;73(6):1086-1093.

26. Tremblay MS, Katzmarzyk PT, Willms JD. Temporal trends in overweight and obesity in Canada, 1981-1996. International journal of obesity and related metabolic disorders. Journal of the International Association for the Study of Obesity. Apr 2002;26(4):538-543.

27. Kautiainen S. Overweight and obesity in adolescence secular trends and associations with perceived weight, socio-demographic factors and screen time. Tampere University Press; 2008. Available from http:// tampub.uta.fi/handle/10024/67899. Accessed March 5, 2019.

28. Noh JW, Jo M, Huh T, Cheon J, Kwon YD. Gender Differences and Socioeconomic Status in Relation to Overweight among Older Korean People. PLoS ONE. 2014;9(5):e97990.

29. Rohilla R, Rajput M, Rohilla J, Malik M, Garg D, Verma M. Prevalence and Correlates of Overweight/Obesity Among Adolescents in an Urban City of North India. Journal of Family Medicine and Primary Care. Oct-Dec 2014;3(4):404-408

30. Keino S, Plasqui G, van den Borne B. Household food insecurity access: a predictor of overweight and underweight among Kenyan women. Agriculture \& Food Security. 2014;3(1):2.
31. Tang HK, Dibley MJ, Sibbritt D, Tran HM. Gender and socio-economic differences in BMI of secondary high school students in Ho Chi Minh city. Asia Pac J Clin Nutr. 2007;16(1):74-83.

32. Kimura Y, Nanri A, Matsushita Y, Sasaki S, Mizoue T. Eating behavior in relation to prevalence of overweight among Japanese men. Asia Pac J Clin Nutr. 2011;20(1):29-34.

33. Monteiro CA, Moura EC, Conde WL, Popkin BM. Socioeconomic status and obesity in adult populations of developing countries: a review. Bulletin of the World Health Organization. Dec 2004;82(12):940-946.

34. Kirunda BE, Fadnes LT, Wamani H, Van den Broeck J, Tylleskär T. Population-based survey of overweight and obesity and the associated factors in peri-urban and rural Eastern Uganda. BMC Public Health. 2015;15(1): 1168 .

35. Traversy G, Chaput JP. Alcohol Consumption and Obesity: An Update. Curr Obes Rep 2015;4(122-130).

36. Suter PM. Is alcohol consumption a risk factor for weight gain and obesity? Critical Reviews in Clinical Laboratory Sciences. 2005;42(3): 197-227.

37. Tzotzas T, Vlahavas G, Papadopoulou SK, Kapantais E, Kaklamanou D, Hassapidou M. Marital status and educational level associated to obesity in Greek adults: data from the National Epidemiological Survey. BMC Public Health. 2010;10:732.

38. Beyen TK, Gebregergs GB, Yesuf ME. Overweight and Obesity, and Associated Factors among High School Students in Gondar Town, North West Ethiopia. J Obes Wt Loss therapy. 2013;3(2):1-4.

39. Tesfalem TP, Debebe M. Prevalence and associated factors of overweight and obesity among high school adolescents in urban communities of Hawassa, Southern Ethiopia. Curr Res Nutr Food Sci. 2013;1(1):23-36.

40. Sachithananthan V, Al Rashedi WF. A Study of the Prevalence of Overweight and Obesity in Adolescents and Early Adults Aged 19 to 24 Years and its Relationship to Lifestyle and Dietary Attributes. American Journal of Ethnomedicine. 2014;1(1):30-35.

41. AE Field, SB Austin, MW Gillman, B Rosner, HR Rockett, GA Colditz. Snack food intake does not predict weight change among children and adolescents. International Journal of Obesity. 2004;28:1210-1216.
Diabetes, Metabolic Syndrome and Obesity: Targets and Therapy is an international, peer-reviewed open-access journal committed to the rapid publication of the latest laboratory and clinical findings in the fields of diabetes, metabolic syndrome and obesity research Original research, review, case reports, hypothesis formation, expert opinion and commentaries are all considered for publication. The manuscript management system is completely online and includes a very quick and fair peer-review system, which is all easy to use. Visit http://www.dovepress.com/testimonials.php to read real quotes from published authors. 